\title{
miR-148a modulates the viability, migration and invasion of oral squamous cell carcinoma cells by regulating HLA-G expression
}

\author{
YUYING ZHANG, XIN JIN and JIE WANG \\ Department of Stomatology, The First People's Hospital of Jining, Jining, Shandong 272100, P.R. China
}

Received July 1, 2018; Accepted February 2, 2019

DOI: $10.3892 / \mathrm{mmr} .2019 .10280$

\begin{abstract}
Oral squamous cell carcinoma (OSCC) is a common malignancy of the oral and maxillofacial regions. MicroRNAs (miRs) are a group of endogenous small noncoding RNAs that inhibit gene expression by binding to the mRNA of target genes, and serve important roles in numerous biological processes. Reverse transcription-quantitative polymerase chain reaction and western blotting were used to detect gene and protein expression levels, respectively. Cell proliferation, migration and invasion were detected using MTT, wound healing and Matrigel assays, respectively. The association between miR-148a and human leukocyte antigen-G (HLA-G) was analyzed using Targetscan and Luciferase reporter assays. In the present study, miR-148a was revealed to be significantly downregulated in OSCC cells. To further investigate the functions of miR-148a in OSCC, the viability, migration, and invasive abilities of SCC-9 cells were investigated following transfection with miR-148a mimics or miR-148a inhibitor. It was revealed that transfection with miR-148a mimics significantly reduced the viability, migration and invasion of cells, whereas miR-148a inhibitor significantly enhanced these properties. In addition, HLA-G was identified as a direct target of miR-148a and demonstrated to be downregulated in OSCC cells. Furthermore, it was revealed that transfection with miR-148a mimics decreased the expression levels of HLA-G mRNA and protein in SCC-9 cells, whereas transfection with miR-148a inhibitor increased the expression of HLA-G mRNA and protein. The results indicated that there was an association between miR-148a and HLA-G expression, and suggested that miR-148a may be a potential target in the treatment of OSCC.
\end{abstract}

Correspondence to: Dr Jie Wang, Department of Stomatology, The First People's Hospital of Jining, 6 Jiankang Road, Jining, Shandong 272100, P.R. China

E-mail: wangjie1806@163.com

Key words: microRNA-148a, oral squamous cell carcinoma, human leukocyte antigen-G, migration, invasion

\section{Introduction}

Oral squamous cell carcinoma (OSCC) is a common malignancy of the oral and maxillofacial regions (1-3). Local infiltration and distant metastasis are the leading causes of patient mortality (4). Numerous studies have reported that the development of tumors is dependent upon the interactions between cancer cells and the tumor microenvironment, in addition to the malignant proliferation of cancer cells (5). The microenvironment is associated with the invasion, metastasis and prognosis of OSCC (6). Investigation into the involvement of human leukocyte antigens (HLAs) in tumor development is important for improved understanding of tumor immunology (7). HLA-G is a non-classical HLA Class-Ib molecule and was first identified in placental extravillous trophoblast (EVT) cells $(8,9)$. It has been demonstrated that HLA-G serves an important role in maternal-fetal immune tolerance (10). HLA-G is an immune tolerance molecule that binds to the immunosuppressive receptors of natural killer (NK) and T cells to inhibit these cells, and induce immunosuppressive signaling (11). The study of HLA-G has expanded from reproduction to organ transplantation, autoimmune diseases and tumor research (12-15), with the role of HLA-G in the immune invasion of tumors of particular interest.

MicroRNAs (miRNAs/miRs) are a group of endogenous small noncoding RNAs (21-23 nucleotides in length) in eukaryotes (16). miRNAs do not encode proteins, but inhibit the expression of genes by binding to the 3 '-untranslated regions (3'-UTRs) of target mRNAs (17-19). It was reported that the abnormal expression of miR-148a was associated with the occurrence and development of various tumors, such as ovarian and non-small cell lung cancer $(20,21)$. Therefore, the expression of miR-148a is considered to possess potential clinical value.

Previous studies have reported that HLA-G is a target of miR-148a (22-24). HLA-G serves an important role in the development and metastasis to lymph nodes of OSCC (25). Increased expression of HLA-G in metastatic OSCC is associated with poor clinical prognosis (26). These findings indicated that miR-148a may serve important roles in OSCC; however, the expression and effects of miR-148a in OSCC remain unclear. In the present study, the expression of miR-148a in an OSCC cell line and normal oral cell line was determined, and its effects on the viability, migration and invasion of OSCC 
cells was investigated. The results indicated that miR-148a may serve as a novel molecular target in the diagnosis and treatment of OSCC.

\section{Materials and methods}

Cell culture and cell transfection. The OSCC cell line SCC9 and the primary normal human oral keratinocyte (HOK) cells were purchased from the American Type Culture Collection (Manassas, VA, USA). The human OSCC cell line, SCC-9, was cultured in a 1:1 mixture of Dulbecco's modified Eagle's medium (DMEM; Gibco; Thermo Fisher Scientific, Inc., Waltham, MA, USA) and Ham's F12 medium (Gibco; Thermo Fisher Scientific, Inc.) containing $1.2 \mathrm{~g} / 1$ sodium bicarbonate, $2.5 \mathrm{mM}$ L-glutamine, $15 \mathrm{mM}$ HEPES and $0.5 \mathrm{mM}$ sodium pyruvate supplemented with $400 \mathrm{ng} / \mathrm{ml}$ hydrocortisone and $10 \%$ fetal bovine serum (FBS; Gibco; Thermo Fisher Scientific, Inc.). Cells were incubated in a humidified incubator at $37^{\circ} \mathrm{C}$ with $5 \% \mathrm{CO}_{2}$. SCC-9 cells were transfected with $50 \mathrm{nM}$ miR-148a inhibitor (miR-148a inhibitor, 5'-ACAAAG UUCUGUAGUGCACUGA-3'), $100 \mathrm{nM}$ miR-148a mimics (miR-148a mimic forward, 5'-UCAGUGCAUGACAGA ACUUGG-3' and reverse, 5'-AAGTTCUGUCAUGCACUG AUU-3') or $50 \mathrm{nM}$ negative control miRNA (NC) (NC forward, 5'-UUCUCCGAACGUGUCACGUTT-3' and reverse, 5'-ACG UGACACGUUCGGAGAATT-3') using Lipofectamine ${ }^{\circledR} 2000$ (Invitrogen; Thermo Fisher Scientific, Inc.) for $48 \mathrm{~h}$ according to the manufacturer's protocols. miR-148a inhibitor, mimic and the NC were purchased from Guangzhou RiboBio Co., Ltd. (Guangzhou, China).

Reverse transcription-quantitative polymerase chain reaction $(R T-q P C R)$. Total RNA was extracted from cells using TRIzol $^{\circledR}$ reagent (Thermo Fisher Scientific, Inc.) according to the manufacturer's protocols and stored at $-80^{\circ} \mathrm{C}$. The total RNA concentration was determined using a NanoDrop 2000 spectrophotometer (NanoDrop Technologies; Thermo Fisher Scientific, Inc., Wilmington, DE, USA). Total RNA was reverse transcribed into cDNA using the PrimeScript RT reagent kit (Takara Bio, Inc., Otsu, Japan) according to the manufacturer's protocol. qPCR was performed using SYBR Green Premix Ex Taq (Takara Bio, Inc.), and the reaction conditions were as follows: $10 \mathrm{~min}$ at $95^{\circ} \mathrm{C}$, followed by 35 cycles of $15 \mathrm{sec}$ at $95^{\circ} \mathrm{C}$ and $40 \mathrm{sec}$ at $55^{\circ} \mathrm{C}$. The primer sequences used for qPCR were as following: GAPDH, forward, 5'-CTTTGGTAT CGTGGAAGGACTC-3' and reverse, 5'-GTAGAGGCAGGG ATGATGTTCT-3'; U6, forward, 5'-GCTTCGGCAGCACAT ATACTAAAAT-3' and reverse, 5'-CGCTTCACGAATTTG CGTGTCAT-3'; miR-148a, forward, 5'-TCGTCACACAGA ACTTTGT-3' and reverse, 5'-GCTGTCACGAGCTCGT-3'; HLA-G, forward, 5'-GAGGAGACACGGAACACCAAG-3' and reverse, 5'-GTCGCAGCCAATCATCCACT-3'; $\beta$-catenin, forward, 5'-GCTTTCAGTTGAGCTGACCA-3' and reverse, 5'-CAAGTCCAAGATCAGCAGTCTC-3'; matrix metalloproteinase-7 (MMP7), forward, 5'-TGTGGAGATGAAGCTTCT GGCTGT-3' and reverse, 5'-TGGTACAATCGTTTCTGC TGGCAC-3'; and T-cell factor-4 (TCF-4), forward, 5'-CAG TCTTCCTCCGATGTC-3' and reverse, 5'-CCCGCTTCC TCTATTTGC-3'. The relative expression levels of genes were normalized to U6 for miRNA or GAPDH for mRNA, and calculated using the $2^{-\Delta \Delta C q}$ method (27). All experiments were performed in triplicate.

Western blot analysis. Cells were washed three times with cold PBS and total cellular proteins were extracted using a modified radioimmunoprecipitation assay buffer (OriGene Technologies, Inc., Beijing, China) with $1 \mathrm{mM}$ phenylmethane sulfonyl fluoride for $30 \mathrm{~min}$. A bicinchoninic acid protein assay kit (Thermo Fisher Scientific, Inc.) was used to measure the protein concentration. Equal amounts of protein (30 $\mu \mathrm{g} / \mathrm{lane})$ were separated via $10 \%$ SDS-PAGE and transferred onto polyvinylidene difluoride membranes. The membranes were blocked with $5 \%$ non-fat milk at room temperature for $1.5 \mathrm{~h}$, followed by incubation overnight at $4{ }^{\circ} \mathrm{C}$ with the following primary antibodies against: HLA-G (1:1,000; ab135736; Abcam, Cambridge, UK), MMP7 (1:1,000; cat. no. 3801; Cell Signaling Technology, Inc., Danvers, MA, USA); $\beta$-catenin (1:1,000; cat. no. 8480, Cell Signaling Technology, Inc.); TCF-4 (1:1,000; cat. no. 2565; Cell Signaling Technology, Inc.) and GAPDH (1:1,000; cat. no. 5174; Cell Signaling Technology, Inc.). The membranes were subsequently incubated for $2 \mathrm{~h}$ at room temperature with an anti-rabbit immunoglobulin $\mathrm{G}$ horseradish peroxidase-conjugated secondary antibody (1:2,000; cat. no. 7074; Cell Signaling Technology, Inc.). Protein bands were visualized using an enhanced chemiluminescence kit (Applygen Technologies, Inc., Beijing, China). GAPDH was used as an internal control.

MTT assay. An MTT assay was performed to determine the viability of cells. Cells were inoculated in a 96-plate with $1 \times 10^{4}$ cells/well and incubated at $37^{\circ} \mathrm{C}$ with $5 \% \mathrm{CO}_{2}$ for 12 , 24 or $48 \mathrm{~h}$. In detail, $20 \mu \mathrm{l}$ MTT reagent $(5 \mathrm{mg} / \mathrm{ml})$ was added to the wells. Following incubation for a further $4 \mathrm{~h}$ at $37^{\circ} \mathrm{C}$, the formazan crystals were dissolved in $150 \mu \mathrm{l}$ dimethyl sulfoxide and agitated for $10 \mathrm{~min}$. The absorbance at $490 \mathrm{~nm}$ was detected using a microplate reader.

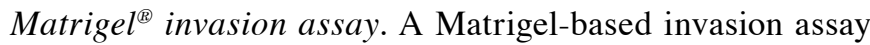
was performed to evaluate the invasive ability of cells. The wells on the upper chamber of Transwell plates were coated with Matrigel. DMEM was then added to the upper chamber and incubated at $37^{\circ} \mathrm{C}$ for $1 \mathrm{~h}$. Cells were seeded in the upper chamber at a density of $5 \times 10^{4}$ cells/well in $100 \mu \mathrm{l}$ serum-free DMEM. DMEM medium containing 20\% FBS (Gibco; Thermo Fisher Scientific, Inc.) was added to the lower chamber (24-well plate). The cells were incubated at $37^{\circ} \mathrm{C}$ for $24 \mathrm{~h}$; then, the lower membranes of the chamber were fixed with $4 \%$ paraformaldehyde at room temperature for $30 \mathrm{~min}$ and stained with $0.1 \%$ crystal violet at room temperature for $20 \mathrm{~min}$. Images of five randomly selected fields per view were captured using a light microscope (magnification, x200) and the numbers of cells were counted.

Luciferase reporter assay. TargetScan 7.1 bioinformatics software (www.targetscan.org/vert_71) was used to predict the targets of miR-148a; it was revealed that HLA-G was a potential target of miR-148a. To investigate the association between miR-148a and HLA-G, the wild-type (WT) and mutant (MUT) 3'-UTRs of HLA-G were cloned into pmiR-RB-Report ${ }^{\mathrm{TM}}$ dual-luciferase reporter gene plasmid 

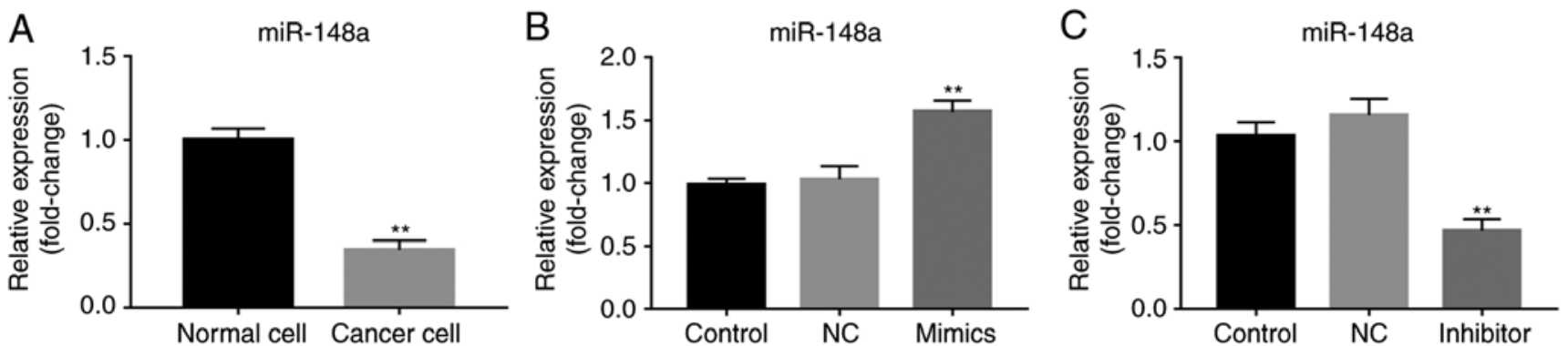

Figure 1. miR-148a is downregulated in OSCC cells. (A) Relative expression of miR-148a in cancer cells (SCC-9) and normal cells (human oral keratinocytes), as determined by reverse transcription-quantitative polymerase chain reaction analysis ( ${ }^{* *} \mathrm{P}<0.01$ vs. normal cell). (B) Relative expression of miR-148a in OSCC cells following transfection with miR-148a mimics ( ${ }^{* *} \mathrm{P}<0.01 \mathrm{vs}$. NC). (C) Relative expression of miR-148a in OSCC cells following transfection with miR-148a mimics $\left({ }^{* *} \mathrm{P}<0.01\right.$ vs. NC). Data are presented as the mean \pm standard deviation. OSCC, oral squamous cell carcinoma; control, non-transfected cells; miR-148a, microRNA-148a; inhibitor, miR-148a inhibitor; mimics, miR-148a mimics; NC, negative control.

vectors (Guangzhou RiboBio Co., Ltd., Guangzhou, China) according to the manufacturer's protocols. Cells seeded in 24 -well plates $\left(5 \times 10^{4}\right.$ cells/well $)$ were co-transfected with miR-148a mimics or NC, and the WT or MUT 3'-UTR using Lipofectamine 2000 for $48 \mathrm{~h}$. The relative luciferase activity was then determined using the dual-luciferase reporter assay system (Promega Corporation, Madison, WI, USA) according to the manufacturer's protocol. Relative luciferase activity was normalized to Renilla luciferase activity.

Scratch-wound assay. A scratch-wound assay was performed to investigate the migratory ability of cells. Cells were seeded in 6 -well plates $\left(5 \times 10^{5}\right.$ cells $\left./ \mathrm{ml}\right)$, wounded with a pipette tip and washed with PBS to remove dead cells. Subsequently, $2 \mathrm{ml}$ culture medium was added to wells. The distance of cell migration was determined after a 24 -h incubation at $37^{\circ} \mathrm{C}$ using an inverted light microscope (Olympus Corporation, Tokyo, Japan; magnification, x100). The wound area was analyzed in five randomly-selected fields of view using ImageJ software (version 1.46; National Institutes of Health, Bethesda, MD, USA).

Statistical analysis. Data were presented as the mean \pm standard deviation of at least three independent experiments. Differences between groups were analyzed using Student's $\mathrm{t}$-tests or one-way factorial analyses of variance followed by a Tukey's post-hoc test. $\mathrm{P}<0.05$ was considered to indicate a statistically significant difference. Data were analyzed using GraphPad Prism 6.0 (GraphPad Software, Inc., La Jolla, CA, USA).

\section{Results}

Expression of miR-148a in OSCC. To investigate the role of miR-148a in OSCC, RT-qPCR analysis was performed to determine the relative expression of miR-148a in the human OSCC cell line, SCC-9 and normal human oral keratinocytes (HOK). It was revealed that miR-148a was significantly downregulated in SCC-9 cells compared with HOK cells (Fig. 1A). To investigate the effects of miR-148a on SCC-9 cells, cells were transfected with NC, miR-148a mimics or miR-148a inhibitor for $48 \mathrm{~h}$. RT-qPCR analysis was conducted to determine the expression levels of miR-148a. It was demonstrated that miR-148a mimics significantly upregulated the expression of miR-148a in SCC-9 cells compared with the control, whereas miR-148a inhibitor exhibited opposing effects (Fig. 1B and C).

Effects of miR-148a on the viability, migration and invasion of OSCC cells. The viability of SCC-9 cells following transfection was analyzed using an MTT assay. It was demonstrated that miR-148a mimics significantly reduced the viability of cells compared with the control (Fig. 2A). The migration of cells was determined via a scratch-wound assay. Cell migration was markedly reduced following transfection with miR-148a mimics compared with the control (Fig. 2B). Additionally, a Matrigel invasion assay demonstrated that the invasive ability of SCC-9 cells was notably decreased following the overexpression of miR-148a (Fig. 2C). Conversely, transfection with miR-148a inhibitor induced opposing effects on the viability, migration and invasion of SCC-9 cells.

Effects of miR-148a on the expression of invasion and migration-associated proteins in oral squamous cell carcinoma. To further investigate the effects of miR-148a on the migration and invasion of SCC-9 cells, the expression of proteins involved in the $\mathrm{Wnt} / \beta$-catenin signaling pathway was analyzed. It was revealed that overexpression of miR-148a markedly downregulated the expression of HLA-G, $\beta$-catenin, MMP-7 and TCF-4 at the protein level, but significantly downregulated their expression at the mRNA level compared with the control (Fig. 3A-E). Conversely, transfection with miR-148a inhibitor notably increased the expression of these proteins; however, significant increases were observed at the mRNA level (Fig. 3F-J).

$H L A-G$ is direct target gene of miR-148a. TargetScan was employed to identify putative targets of miR-148a. Binding sites for miR-148a were identified in the 3'-UTRs of numerous genes, including HLA-G (Fig. 4A). HLA-G has been reported to serve important roles in the development of OSCC (25) and its expression is associated with the clinical prognosis of patients with OSCC (26). To further investigate the potential interaction between miR-148a and the 3'-UTR of HLA-G, dual-luciferase reporter plasmids were constructed containing the WT or MUT 3'-UTR of HLA-G. Luciferase reporter assays revealed that miR-148a mimics significantly reduced the 

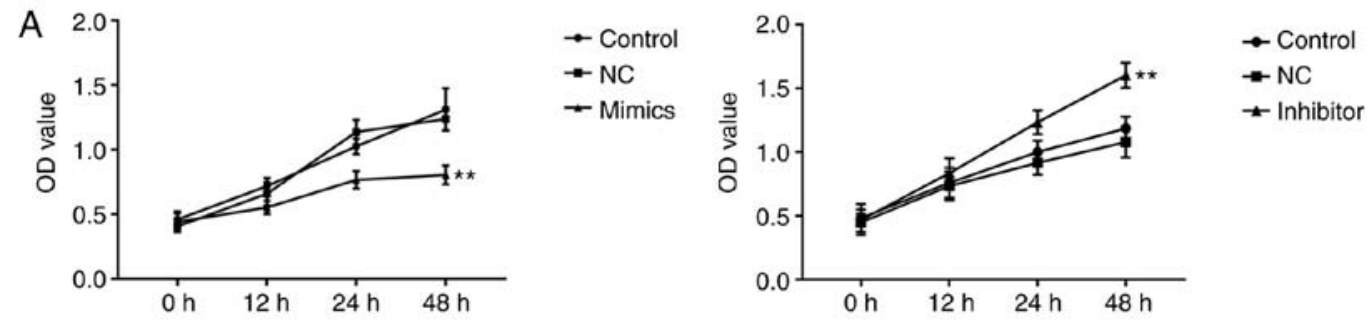
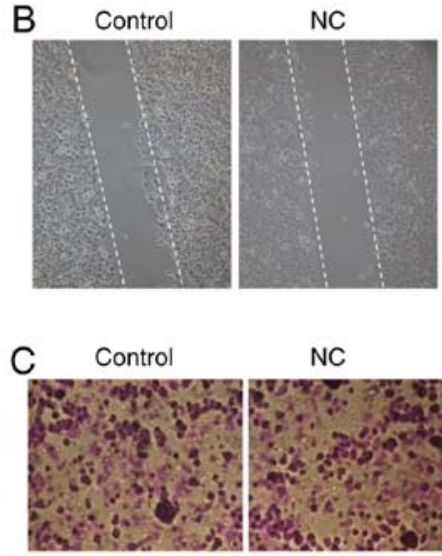

NC

NC

Mimics

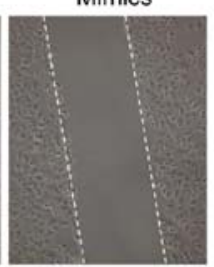

Mimics
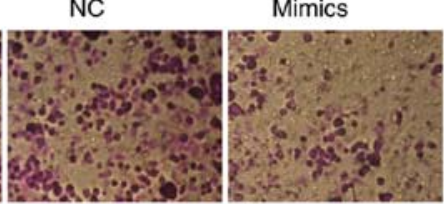
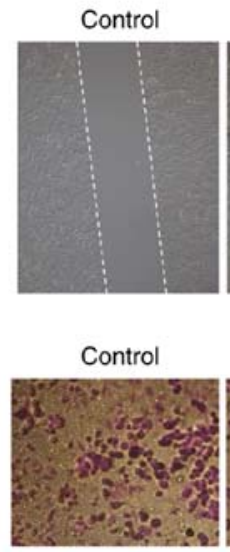

NC

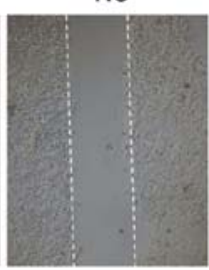

NC

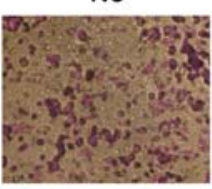

Inhibitor

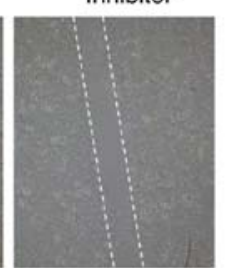

Inhibitor

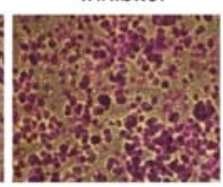

Figure 2. miR-148a suppresses the viability, migration and invasion of oral squamous carcinoma cells. (A) Viability of SCC-9 cells at 12,24 and $48 \mathrm{~h}$ following transfection with miR-148a mimics or miR-148a inhibitor, as determined by an MTT assay. (B) Migration of SCC-9 cells following transfection with miR-148a mimics or miR-148a inhibitor for $48 \mathrm{~h}$, as determined by a scratch-wound assay (magnification, $\mathrm{x} 200$ ). (C) Invasion of SCC-9 cells following transfection with miR-148a mimics or miR-148a inhibitor for $48 \mathrm{~h}$, as determined using a Matrigel-based invasion assay (magnification, $\mathrm{x} 100$ ). Data are presented as the mean \pm standard deviation. Control, non-transfected cells; miR-148a, microRNA-148a; inhibitor, miR-148a inhibitor; mimics, miR-148a mimics; NC, negative control; OD, optical density. ${ }^{* *} \mathrm{P}<0.01$ vs. NC.

luciferase activity in cells transfected with reporters containing the WT, but not the MUT HLA-G 3'-UTR compared with the control (Fig. 4B). The results provided indicated that HLA-G was a direct target of miR-148a. RT-qPCR was conducted to determine the expression levels of HLA-G mRNA in HOK and SCC-9 cells. It was demonstrated that HLA-G was significantly upregulated in SCC-9 cells compared with normal cells (Fig. 4C).

\section{Discussion}

It has been reported that miRNAs serve important roles in the regulation of the viability, invasion and migration of cells (28-30). In addition, miRNA dysregulation is involved in the initiation and progression of cancer (31-33). Therefore, miRNAs have received increasing focus as potential therapeutic targets. Previous studies have identified the involvement of various miRNAs in the initiation and progression of oral cancer, including miR-31, miR-139, miR-195, miR-21, miR-221 and miR-455 (34-42). Numerous studies have reported the downregulation of miR-148a in various cancers, including gastric and breast cancers, and esophageal squamous cell carcinoma $(22,24)$, suggesting it exhibits tumor suppressor roles in cancer cells. In the present study, miR-148a was observed to be downregulated in the OSCC cell line, SCC-9 compared with normal cells. Overexpression of miR-148a suppressed the viability, migration and invasive ability of SCC-9 cells. Furthermore, a previous study demonstrated that miR-148a induced the apoptosis of numerous colorectal cancer cell lines, in which Bcl-2 was identified as a direct target (43).
miRNAs can function as oncogenes or tumor suppressors via interactions with specific targets $(44,45)$, HLA-G was identified as a direct target gene of miR-148a. HLA-G is a non-classical HLA-class Ib molecule expressed in EVT cells $(8,9)$. It serves important roles in the establishment of healthy pregnancy; it induces maternal immune tolerance and directly affects the function of trophoblast cells, regulating prefoldin and MMP expression in an autocrine manner (46). Previous studies reported that HLA-G was preferentially expressed in tumor tissues and rarely in adjacent normal tissues, suggesting that it is associated with tumor growth and development $(47,48)$. The findings of the present study revealed that transfection with miR-148a mimics significantly inhibited the expression of HLA-G in OSCC cells, whereas miR-148a inhibitor upregulated HLA-G expression. Additionally, it was demonstrated that miR-148a mimics suppressed the expression of $\beta$-catenin, MMP-7 and TCF-4, whereas transfection with miR-148a inhibitor exhibited opposing effects.

In conclusion, miR-148a suppressed the viability, migration and invasion of OSCC cells, potentially via interactions with HLA-G. Thus, targeting the miR-148a/HLA-G interaction may be a novel therapeutic strategy in the treatment of OSCC; however, the present study is only a preliminary investigation into the roles of miR-148a in OSCC. Additional studies are required to determine the expression and role of HLA-G in OSCC tissues, the effects of miR-148a on OCSS in vivo and the association between the expression of miR-148a/HLA-G and the clinical characteristics and prognosis of patients with OSCC. 

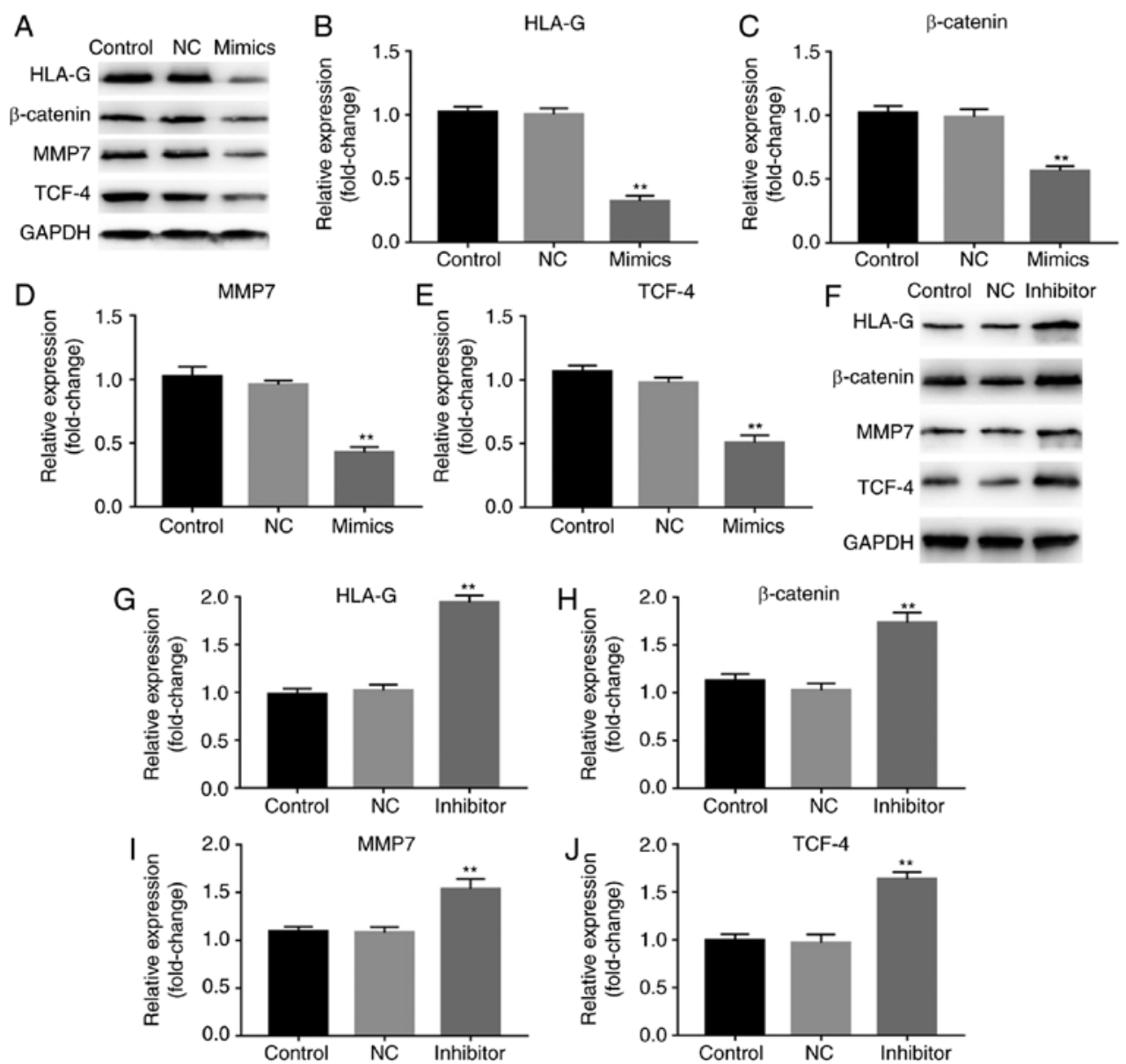

Figure 3. miR-148a downregulates the expression of invasion and migration-associated proteins in oral squamous carcinoma cells. (A) Representative western blot of HLA-G, $\beta$-catenin, MMP-7 and TCF-4 expression in SCC-9 cells following transfection with miR-148a mimics. mRNA expression of (B) HLA-G, (C) $\beta$-catenin, (D) MMP-7 and (E) TCF-4 in SCC-9 cells following transfection with miR-148a mimics, as determined by RT-qPCR. (F) Representative western blot of HLA-G, $\beta$-catenin, MMP-7 and TCF-4 expression in SCC-9 cells following transfection with miR-148a inhibitor. mRNA expression of (G) HLA-G, (H) $\beta$-catenin, (I) MMP-7 and (J) TCF-4 in SCC-9 cells following transfection with miR-148a inhibitor, as determined by RT-qPCR. Data are presented as the mean \pm standard deviation. Control, non-transfected cells; HLA-G, human leukocyte antigen-G; miR-148a, microRNA-148a; inhibitor, miR-148a inhibitor; mimics, miR-148a mimics; MMP-7, metalloproteinase-7; NC, negative control; RT-qPCR, reverse transcription-quantitative polymerase chain reaction; TCF-4, T-cell factor- $4 .{ }^{* *} \mathrm{P}<0.01$ vs. NC.

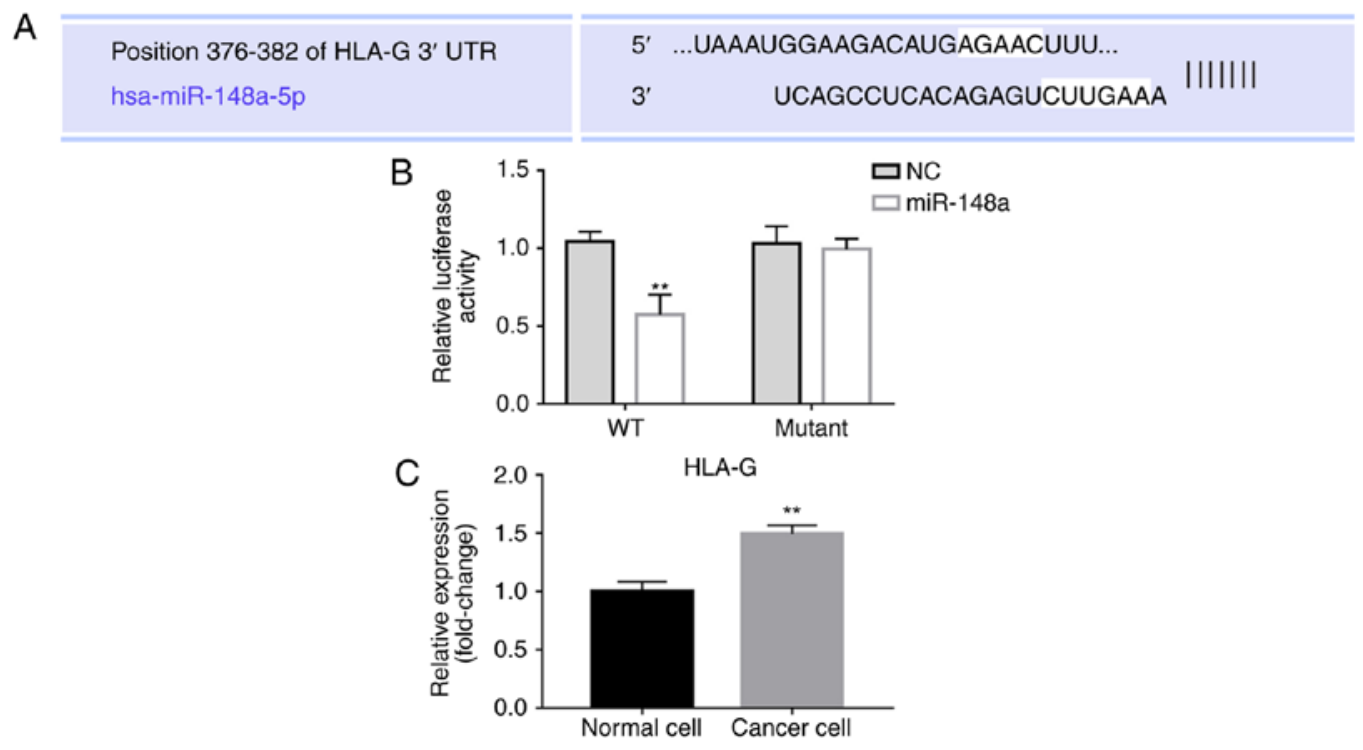

Figure 4. HLA-G is direct target of miR-148a. (A) miR-148a binding site in the 3'-UTR of HLA-G, as predicted by TargetScan. (B) Luciferase activity of SCC-9 cells co-transfected with luciferase reporter plasmids containing the WT or mutant 3'-UTR of HLA-G and miR-148a mimics or NC. ${ }^{* *} \mathrm{P}<0.01$ vs. NC. (C) Relative mRNA expression of HLA-G in cancer (SCC-9) and normal cells (human oral keratinocytes). ${ }^{* *} \mathrm{P}<0.01$ vs. normal cells). Data are presented as the mean \pm standard deviation. HLA-G, human leukocyte antigen-G; miR-148a, microRNA-148a; NC, negative control; 3'-UTR, 3'-untranslated region; WT, wild-type. 


\section{Acknowledgements}

Not applicable.

\section{Funding}

No funding was received.

\section{Availability of data and materials}

The datasets used/or and analyzed during the current study are available from the corresponding author on reasonable request.

\section{Authors' contributions}

YZ designed the present study. YZ and XJ collected and analyzed the data. JW analyzed the data and drafted the manuscript. All authors interpreted the data and wrote the manuscript. All authors read and approved the final version of the manuscript.

\section{Ethics approval and consent to participate}

Not applicable.

\section{Patient consent for publication}

Not applicable.

\section{Competing interests}

The authors declare that they have no competing interests.

\section{References}

1. Tang H, Wu Z, Zhang J and Su B: Salivary lncRNA as a potential marker for oral squamous cell carcinoma diagnosis. Mol Med Rep 7: 761-766, 2013.

2. Zhao E, Xu J, Yin X, Sun Y, Shi J and Li X: Detection of deregulated pathways to lymphatic metastasis in oral squamous cell carcinoma. Pathol Oncol Res 15: 217-223, 2009.

3. Singh P, Barpande SR, Bhavthankar JD, Mandale MS and Bhagwat AU: Serum Cyfra 21-1 levels in oral squamous cell carcinoma patients and its clinicopathologic correlation. Indian J Dent Res 28: 162-168, 2017.

4. Jerjes W, Upile T, Petrie A, Riskalla A, Hamdoon Z, Vourvachis M, Karavidas K, Jay A, Sandison A, Thomas GJ, et al Clinicopathological parameters, recurrence, locoregional and distant metastasis in $115 \mathrm{~T} 1-\mathrm{T} 2$ oral squamous cell carcinoma patients. Head Neck Oncol 2: 9, 2010.

5. Rich A, Hussaini H, Parachuru P and Seymour G: The tumour microenvironment in oral squamous cell carcinoma. Pathology 46 (Suppl 1): S9, 2014.

6. Kato K, Hara A, Kuno T, Kitaori N, Huilan Z, Mori H, Toida M and Shibata T: Matrix metalloproteinases 2 and 9 in oral squamous cell carcinomas: Manifestation and localization of their activity. J Cancer Res Clin Oncol 131: 340-346, 2005.

7. Shahrabi S, Hadad EH, Asnafi AA, Behzad MM, Ehsanpour A and Saki N: Human leukocyte antigens in cancer metastasis: Prognostic approach and therapeutic susceptibility. Histol Histopathol 34: 111-124, 2019.

8. Alizadeh N, Mosaferi E, Farzadi L, Majidi J, Monfaredan A, Yousefi B and Baradaran B: Frequency of null allele of human leukocyte antigen-G (HLA-G) locus in subjects to recurrent miscarriage. Int J Reprod Biomed (Yazd) 14: 459-464, 2016.

9. Yie SM, Li LH, Xiao R and Librach CL: A single base-pair mutation in the 3'-untranslated region of HLA-G mRNA is associated with pre-eclampsia. Mol Hum Reprod 14: 649-653, 2008.
10. Ferreira LM, Meissner TB, Tilburgs T and Strominger JL: HLA-G: At the interface of maternal-fetal tolerance. Trends Immunol 38: 272-286, 2017.

11. Bian X, Si Y, Zhang M, Wei R, Yang X, Ren H, Zheng G, Wang C and Zhang Y: Down-expression of miR-152 lead to impaired anti-tumor effect of NK via upregulation of HLA-G. Tumour Biol 37: 3749-3756, 2016.

12. Costa CH, Gelmini GF, Nardi FS, Roxo VM, Schuffner A and da Graça Bicalho M: HLA-G profile of infertile couples who underwent assisted reproduction treatment. Hum Immunol 77: 1179-1186, 2016.

13. Lazarte J, Adamson MB, Tumiati LC and Delgado DH: 10-year experience with HLA-G in heart transplantation. Hum Immunol 79: 587-593, 2018.

14. Beneventi F, Badulli C, Locatelli E, Caporali R, Ramoni V, Cavagnoli C, Simonetta M, Garbin G, Tinelli C, Alpini C, et al: Soluble HLA-G in pregnancies complicated by autoimmune rheumatic diseases. J Reprod Immunol 110: 67-73, 2015.

15. Seliger B: Role of microRNAs on HLA-G expression in human tumors. Hum Immunol 77: 760-763, 2016.

16. Li X, Liu F, Lin B, Luo H, Liu M, Wu J, Li C, Li R, Zhang X, Zhou K and Ren D: miR-150 inhibits proliferation and tumorigenicity via retarding G1/S phase transition in nasopharyngeal carcinoma. Int J Oncol 50: 1097-1108, 2017.

17. Ro S, Park C, Young D, Sanders KM and Yan W: Tissue-dependent paired expression of miRNAs. Nucleic Acids Res 35: 5944-5953, 2007.

18. Mallory AC and Vaucheret H: MicroRNAs: Something important between the genes. Curr Opin Plant Biol 7: 120-125, 2004.

19. Garzon R, Calin GA and Croce CM: MicroRNAs in cancer. Annu Rev Med 60: 167-179, 2009.

20. Zhou X, Zhao F, Wang ZN, Song YX, Chang H, Chiang Y and Xu HM: Altered expression of miR-152 and miR-148a in ovarian cancer is related to cell proliferation. Oncol Rep 27: 447-454, 2012.

21. Yang JS, Li BJ, Lu HW, Chen Y, Lu C, Zhu RX, Liu SH, Yi QT, Li J and Song CH: Serum miR-152, miR-148a, miR-148b, and miR-21 as novel biomarkers in non-small cell lung cancer screening. Tumour Biol 36: 3035-3042, 2015.

22. Chen Q, Luo G and Zhang X: MiR-148a modulates HLA-G expression and influences tumor apoptosis in esophageal squamous cell carcinoma. Exp Ther Med 14: 4448-4452, 2017.

23. Sun J, Chu H, Ji J, Huo G, Song Q and Zhang X: Long non-coding RNA HOTAIR modulates HLA-G expression by absorbing miR-148a in human cervical cancer. Int J Oncol 49: 943-952, 2016.

24. Tao S, He H, Chen Q and Yeu W: GPER mediated estradiol reduces miR-148a to promote HLA-G expression in breast cancer. Biochem Biophys Res Commun 451: 74-78, 2014.

25. Imani R, Seyedmajidi M, Ghasemi N, Moslemi D, Shafaee S and Bijani A: HLA-G expression is associated with an unfavorable prognosis of oral squamous cell carcinoma. Asian Pac J Cancer Prev 19: 2527-2533, 2018.

26. Gonçalves AS, Wastowski IJ, Capeletti LR, Sacono NT, Cortez AP, Valadares MC, Silva TA and Batista AC: The clinicopathologic significance of the expression of HLA-G in oral squamous cell carcinoma. Oral Surg Oral Med Oral Pathol Oral Radiol 117: 361-368, 2014.

27. Livak KJ and Schmittgen TD: Analysis of relative gene expression data using real-time quantitative PCR and the 2(-Delta Delta C(T)) method. Methods 25: 402-408, 2001.

28. Cui Z, Liu G and Kong D: miRNA-27a promotes the proliferation and inhibits apoptosis of human pancreatic cancer cells by Wnt/ $\beta$-catenin pathway. Oncol Rep 39: 755-763, 2018.

29. Mo D, Yang D, Xiao X, Sun R, Huang L and Xu J: MiRNA-145 suppresses lung adenocarcinoma cell invasion and migration by targeting N-cadherin. Biotechnol Lett 39: 701-710, 2010.

30. Liu F, Zhang G, Lv S, Wen X and Liu P: miRNA-301b-3p accelerates migration and invasion of high-grade ovarian serous tumor via targeting CPEB3/EGFR axis. J Cell Biochem: Mar 4, 2019 (Epub ahead of print). doi: 10.1002/jcb.28528.

31. Calin GA and Croce CM: MicroRNA signatures in human cancers. Nat Rev Cancer 6: 857-866, 2006.

32. Esquela-Kerscher A and Slack FJ: Oncomirs-microRNAs with a role in cancer. Nat Rev Cancer 6: 259-269, 2006

33. Kent OA and Mendell JT: A small piece in the cancer puzzle: microRNAs as tumor suppressors and oncogenes. Oncogene 25: 6188-6196, 2006.

34. Chang KW, Kao SY, Wu YH, Tsai MM, Tu HF, Liu CJ, Lui MT and Lin SC: Passenger strand miRNA miR-31* regulates the phenotypes of oral cancer cells by targeting RhoA. Oral Oncol 49: 27-33, 2013. 
35. Chawla JP, Iyer N, Soodan KS, Sharma A, Khurana SK and Priyadarshni P: Role of miRNA in cancer diagnosis, prognosis, therapy and regulation of its expression by Epstein-Barr virus and human papillomaviruses: With special reference to oral cancer. Oral Oncol 51: 731-737, 2015.

36. Ren Y, Zhu H, Chi C, Yang F and Xu X: MiRNA-139 regulates oral cancer Tca8113 cells apoptosis through Akt signaling pathway. Int J Clin Exp Pathol 8: 4588-4594, 2015.

37. Wang F, Jiang C, Sun Q, Yan F, Wang L, Fu Z, Liu T and Hu F: miR-195 is a key regulator of Raf1 in thyroid cancer. Onco Targets Ther 8: 3021-3028, 2015.

38. Wang M, Zhang J, Tong L, Ma X and Qiu X: MiR-195 is a key negative regulator of hepatocellular carcinoma metastasis by targeting FGF2 and VEGFA. Int J Clin Exp Pathol 8: 14110-14120, 2015.

39. Yilaz Susluer S, Biray Avci C, Dodurga Y, Ozlem Dogan Sigva Z, Oktar N and Gunduz C: Downregulation of miR-195 via cyclosporin A in human glioblastoma cells. J BUON 20: 1337-1340, 2015.

40. Li L, Li C, Wang S, Wang Z, Jiang J, Wang W, Li X, Chen J, Liu K, $\mathrm{Li} \mathrm{C}$ and $\mathrm{Zhu} \mathrm{G}$ : Exosomes derived from hypoxic oral squamous cell carcinoma cells deliver miR-21 to normoxic cells to elicit a prometastatic phenotype. Cancer Res 76: 1770-1780, 2016.

41. He S, Lai R, Chen D, Yan W, Zhang Z, Liu Z, Ding X and Chen Y: Downregulation of miR-221 inhibits cell migration and invasion through targeting methyl-CpG binding domain protein 2 in human oral squamous cell carcinoma cells. Biomed Res Int 2015: $751672,2015$.
42. Cheng CM, Shiah SG, Huang CC, Hsiao JR and Chang JY: Up-regulation of miR-455-5p by the TGF- $\beta$-SMAD signalling axis promotes the proliferation of oral squamous cancer cells by targeting UBE2B. J Pathol 240: 38-49, 2016.

43. Zhang H, Li Y, Huang Q, Ren X, Hu H, Sheng H and Lai M: MiR-148a promotes apoptosis by targeting Bcl-2 in colorectal cancer. Cell Death Differ 18: 1702-1710, 2011.

44. Bartel DP: MicroRNAs: Genomics, biogenesis, mechanism, and function. Cell 116: 281-297, 2004.

45. Lagos-Quintana M, Rauhut R, Lendeckel W and Tuschl T: Identification of novel genes coding for small expressed RNAs. Science 294: 853-858, 2001.

46. Liu H, Liu X, Jin H, Yang F, Gu W and Li X: Proteomic analysis of knock-down HLA-G in invasion of human trophoblast cell line JEG-3. Int J Clin Exp Pathol 6: 2451-2459, 2013.

47. Rouas-Freiss N, Moreau P, Ferrone S and Carosella ED: HLA-G proteins in cancer: Do they provide tumor cells with an escape mechanism? Cancer Res 65: 10139-10144, 2005.

48. Tripathi $P$ and Agrawal S: Non-classical HLA-G antigen and its role in the cancer progression. Cancer Invest 24: 178-186, 2006.

(i) (9) This work is licensed under a Creative Commons Attribution-NonCommercial-NoDerivatives 4.0 International (CC BY-NC-ND 4.0) License. 